\title{
A comparative study of propranolol versus silver nitrate cautery in the treatment of recurrent primary epistaxis in children
}

This article was published in the following Dove Press journal:

Adolescent Health, Medicine and Therapeutics

30 September 2015

Number of times this article has been viewed

\author{
Ahmed E Ahmed' \\ Essam A Abo El-Magd ${ }^{2}$ \\ Gamal M Hasan ${ }^{3,4}$ \\ Osama M El-Asheer ${ }^{3}$ \\ 'Pediatric Department, Qena \\ University Hospital, Faculty of \\ Medicine, South Valley University, \\ Qena, Egypt; ${ }^{2}$ Otorhinolaryngology \\ Department, Aswan University \\ Hospital, Faculty of Medicine, Aswan \\ University, Aswan, Egypt; ${ }^{3}$ Pediatric \\ Department, Assiut University \\ Children's Hospital, Faculty of \\ Medicine, Assiut University, Assiut, \\ Egypt; ${ }^{4}$ Pediatric Department, King \\ Khalid University Hospital, King Saud \\ University, Riyadh, Saudi Arabia
}

Background: Epistaxis is a common medical problem in pediatric population. Although in most cases it is mild and self-limiting, a proportion of childhood epistaxis is massive, recurrent, or resistant to conventional management.

Objective: To compare effectiveness of propranolol as a treatment option for childhood epistaxis versus conventional silver nitrate cautery.

Study design and methodology: This is a prospective interventional comparative study that was carried out during a period of 1 year (January 1, 2013 to December 31, 2013) at Qena University Hospital and Assiut University Children's Hospital. One hundred children aged 6-12 years who presented with epistaxis to Qena University Hospital and Assiut University Children's Hospital during the study period and fulfilling the inclusion criteria were included in the study. They were randomly assigned into one of two interventional groups, where 50 children were treated with oral propranolol (propranolol treatment group) and another 50 children were treated with conventional silver nitrate cautery (cauterization treatment group) for their epistaxis. Propranolol was given at a dose of $1.5-2 \mathrm{mg} / \mathrm{kg} /$ day (divided into three doses). Patients were followed for 6 months after their discharge for recurrence of epistaxis.

Results: Both groups of patients showed minimal recurrent epistaxis with rates of $14 \%$ for propranolol treated group and $12 \%$ for cauterization group, with no statistically significant difference between both groups. Local pain was found to be more in patients treated with silver nitrate cauterization.

Conclusion: Treatment of primary epistaxis with propranolol or silver nitrate cautery showed equal rates of recurrence, and local nasal pain was slightly more among silver nitrate cauterization treated group. Propranolol could be a favorable treatment option for patients with primary epistaxis. Further studies that include multiple centers and larger number of patients are recommended for more clarification of the effectiveness of such treatment option.

Keywords: propranolol, silver nitrate cautery, epistaxis, children

\section{Introduction}

Epistaxis is seen in $60 \%$ of the people, and among these, $80 \%$ are from the Keisselbach's plexus, and they are known as anterior epistaxis. ${ }^{1}$ It is one of the common presentations to pediatricians and otolaryngologists. ${ }^{2,3}$ The most common causes are nose picking, trauma, infection, hypertension, etc. ${ }^{4}$ Epistaxis is a common medical problem in pediatric population. Although in most cases it is mild and self-limiting, a proportion of childhood epistaxis is massive, recurrent, or resistant to conventional management. ${ }^{5}$ Till now, there is no sufficient clinical data concerning the usefulness of nonselective beta blockers in treating epistaxis. However, their antagonistic beta-1 and beta- 2 adrenoceptor effects, together with their recently discovered antiangiogenic
Correspondence: Ahmed E Ahmed Pediatric Department, Qena University Hospital, Faculty of Medicine, South Valley University, PO Box 83523, Qena, Egypt

Tel +20 I2 232I 5223

Email yasen I I20I0@gmail.com 
effect, suggest that nonselective beta blockers have potentially useful hemostatic effect. ${ }^{6,7}$ Chemical cautery with silver nitrate is a commonly used modality for the management of epistaxis.

\section{Objectives}

The primary goal of our study was to compare the effectiveness of oral propranolol therapy to conventional silver nitrate cautery in the treatment of children with recurrent epistaxis. Secondary goal was to compare the recurrence rate of epistaxis among the two treatment options used for studied patients.

\section{Study design and methodology Study design}

This study is a prospective randomized clinical trial that was carried out at two Upper Egypt governorates during a period of 1 year (January 1, 2013-December 31, 2013).

\section{Study population and inclusion criteria}

This study included 100 children, aged 6-12 years, presented to Qena University Hospital and Assiut University Children's Hospital during the study period with recurrent primary epistaxis and fulfilling the inclusion criteria. Primary epistaxis was defined as spontaneous nasal bleeding in the absence of an underlying local or systemic cause(s) that might result in such bleeding. Recurrent epistaxis was defined as at least one episode of bleeding per week prior to enrolment to the study, and protracted epistaxis was defined as persistence of this epistaxis for more than 1 month. Inclusion criteria were previous unsuccessful treatment with standard therapy (topical antiseptic cream and local vasoconstrictors), hemodynamically stable, not indicated for blood transfusion, no previously known local or systemic disease that might cause bleeding, not known to have drug allergy, not receiving any anticoagulant medication, and not known to have any disease process that might contraindicate the use of propranolol. A written consent was obtained from the patients and guardian. They were randomly assigned into one of two groups, where 50 children were allocated to propranolol treatment group and another 50 children of matched age and sex were allocated to silver nitrate cauterization group.

\section{Interventions}

Studied patients were subjected to thorough history taking, with special emphasis on medical history, therapeutic history, and drug allergy. Moreover, studied children were subjected to complete physical examination with special focus on local nasal examination for the bleeding points and any comorbid or local causes for epistaxis. Local nasal examination was carried out using head light mirror, nasal speculum, suction, and sometimes local topical mucosal vasoconstrictor was used to identify the bleeding site and to evaluate the nasal mucosa. They were also subjected to rhinoscopy.

Severity of epistaxis was assessed by the frequency of episodes, duration and amount of bleeding, effect of bleeding on hemodynamics, blood hemoglobin level, and the need for blood transfusion. ${ }^{8}$ However, such severity assessment was used mainly for the purpose of selecting patients to be enrolled to the study rather than for therapeutic or prognostic value.

All patients were also subjected to the following investigations prior to enrolment into the study: complete blood counts were taken using Cell Dyn 1800 (Abbott diagnostics, Weisbaden, Germany). Prothrombin time, prothrombin concentration, and activated partial thromboplastin time were calculated using BFT-II analyzer (Siemens Healthcare $\mathrm{GmbH}$, Erlangen, Germany).

The 50 patients in the propranolol treatment group received oral propranolol that was in tablet form and whenever needed, it was prepared as a syrup for easy dosing administration with the aid of clinical pharmacy department at our hospitals (Inderal, Astra Zeneca, Egypt). The average dose of propranolol used was $1.5-2 \mathrm{mg} / \mathrm{kg}$ /day (divided into three doses). Treatment duration continued for a period of at least 2 weeks and a maximum of 1 month depending on the patient's compliance and response.

Parents or guardians of the studied children in the propranolol treatment group received sufficient information about the common side effects of propranolol such as bradycardia, hypotension, anxiety, restlessness, sleep disturbance, chest tightness, hyperventilation, and other less common side effects among pediatric age groups.

The other 50 patients were treated with silver nitrate cautery of the bleeding points/prominent vessels. Patients of both groups were followed up monthly in the outpatient clinic for a period of 6 months after their discharge for the recurrence of epistaxis and/or any side effects of propranolol. Occurrence of only one episode of epistaxis within the first month after the last dose of propranolol or after cauterization was considered as a treatment failure.

\section{Exclusion criteria}

Exclusion criteria included any patient with comorbid intranasal conditions, immunodeficiency status, history of massive bleeding diathesis, posterior epistaxis, active bleeding necessitating blood transfusion, secondary causes of epistaxis, 
history of receiving antiplatelet and or anticoagulant therapy, bradycardia, hypotension, bronchospasm prior to propranolol treatment initiation, development of any serious side effects for propranolol or significant drug reaction, and patients who failed to show during the follow-up.

\section{Ethical considerations}

The study was approved by the Research and Ethical Review Committee of the Faculty of Medicine, South Valley University, and the Research and Ethical Review Committee of the Faculty of Medicine, Assiut University. The study adhered to the World Medical Association Declaration of Helsinki. Written consent was obtained from the parents or patients' guardians upon enrolment to the study after detailed explanation of the study objectives, interventions, and possible benefits to the participants.

\section{Statistical analysis}

Collected data were analyzed using Statistical Package for the Social Science (version 21.0 SPSS Inc., Chicago, IL, USA). Frequencies were calculated for qualitative data, and appropriate tests of significance were used to show statistical differences, and $P$-value was considered significant if $<0.05$.

\section{Results}

The study included 100 children, 54 males and 46 females, and their average age was 6-12 years. There was no significant difference among studied patients in relation to age and sex. Among the 50 patients of propranolol treatment group, seven patients $(14 \%)$ reported to have at least one episode of epistaxis, two patients (4\%) had recurrence of epistaxis in the first month immediately after discontinuation of propranolol, and five patients $(10 \%)$ had recurrence of epistaxis in the last 3 months of their follow-up period, which was minor and self-limiting nasal bleeding. The remaining 43 patients $(86 \%)$ among the propranolol treatment group showed no recurrence of their epistaxis, and no side effects were encountered among all patients in this group. On the other hand, in the silver nitrate cautery treatment group, six patients (12\%) reported to have at least one episode of epistaxis during their follow-up period; one patient had severe epistaxis after 1 week of cauterization and treated with anterior nasal pack; another patient had minor epistaxis and repeated cauterization was done; and the remaining four patients had their epistaxis recurrence in the last 3 months of their follow-up period, which was self-limiting nasal bleeding. There was no statistically significant difference between the two groups in relation to epistaxis recurrence rate. Analgesic use for local nasal pain was noted among patients in the silver nitrate cautery treatment group, whereas the propranolol treatment group did not need any analgesics.

Table 1 shows sex distribution and age groups of the studied patients. Table 2 shows number of patients, different age groups, treatment duration in weeks, rhinoscopy findings, and recurrence rate among patients included in the propranolol treatment group. Table 3 shows number of patients, different age groups, rhinoscopy findings, and recurrence rate among patients included in the silver nitrate cautery treatment group. Table 4 shows the rate of epistaxis recurrence among propranolol treatment group in comparison with silver nitrate cautery treatment group.

\section{Discussion}

Epistaxis is one of the common pediatric emergencies that pediatricians and ENT surgeons are facing in their daily practice. Spontaneous epistaxis is common among different pediatric age groups. In the vast majority of cases, bleeding is minimal and self-limiting, and no specific cause is found, and in the majority of them, bleeding is at the Little's area from Keisselbach's plexus. ${ }^{9}$ Different treatment modalities such as low pressure packs, merocel sponges, chemical or electrical cautery, high pressure balloon packs, or surgical management are available. The majority of such cases can be treated medically rather than surgically. Moreover, most of the patients can be managed on an outpatient basis if there is no any other comorbid condition. ${ }^{10}$ The application of a simple digital pressure with ice packs might be sufficient for the management of the bleeding, though cauterization may be required in some patients. ${ }^{11}$ Silver nitrate cautery represents the most common method of chemical cautery in the outpatient setting.

There is an accumulating evidence for the efficacy of beta blockers in the management of hemangiomas. Little is known about the efficacy of such group of medications in the management of bleeding diathesis. Our study aimed to clarify the role and possible efficacy for such medications in

Table I Sex distribution among different age groups in studied patients

\begin{tabular}{lll}
\hline Age groups (years) & Male $(\mathbf{n})$ & Female $(\mathbf{n})$ \\
\hline 6 to $<7$ & 8 & 7 \\
7 to $<8$ & 9 & 8 \\
8 to $<9$ & 10 & 7 \\
9 to $<10$ & 9 & 9 \\
10 to $<$ II & 8 & 8 \\
II to 12 & 10 & 7 \\
\hline
\end{tabular}


Table 2 Some studied variables among propranolol treatment group

\begin{tabular}{|c|c|c|c|c|}
\hline $\begin{array}{l}\text { Number of } \\
\text { patients }\end{array}$ & $\begin{array}{l}\text { Age group } \\
\text { (years) }\end{array}$ & $\begin{array}{l}\text { Treatment } \\
\text { duration (weeks) }\end{array}$ & Rhinoscopy findings & Epistaxis recurrence ${ }^{a}$ \\
\hline 10 & 6 to $<7$ & 3 & $\begin{array}{l}\text { Bilateral prominent vessels on the anterior } \\
\text { nasal septum }\end{array}$ & One case after discontinuation of treatment \\
\hline 9 & 7 to $<8$ & 2 & Normal findings & One case in the last month \\
\hline 7 & 8 to $<9$ & 2 & $\begin{array}{l}\text { Unilateral dilated vessels on anterior nasal } \\
\text { septum }\end{array}$ & One case in the last month \\
\hline 8 & 9 to $<10$ & 3 & $\begin{array}{l}\text { Bilateral prominent vessels on the anterior } \\
\text { nasal septum }\end{array}$ & One case in the second month \\
\hline 7 & 10 to $<$ II & 3 & $\begin{array}{l}\text { Bilateral prominent vessels on the anterior } \\
\text { nasal septum }\end{array}$ & One case after discontinuation of treatment \\
\hline 9 & II to $<12$ & 4 & $\begin{array}{l}\text { Bilateral prominent vessels on the anterior } \\
\text { nasal septum }\end{array}$ & Two cases within the third month \\
\hline
\end{tabular}

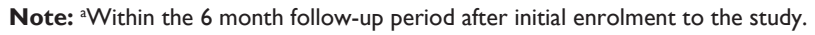

the management of primary, recurrent, nonlife-threatening idiopathic epistaxis in children.

Our study showed that children with primary, recurrent, idiopathic epistaxis and treated with propranolol had favorable response and control of their bleeding. Moreover, no statistically significant difference was found in the recurrence rates of epistaxis episodes among children treated with propranolol (7 [14\%]) and those treated with conventional silver nitrate cautery $(6[12 \%])$.

Our finding that propranolol showed effectiveness in the management of epistaxis in studied patients comes in agreement with Bjelakovic et al who found in their case series that propranolol showed $100 \%$ efficacy in the management of primary idiopathic childhood epistaxis. ${ }^{12}$ Similarly, Albinana et al had suggested that the local administration of propranolol in the nasal mucosa could be a treatment option for epistaxis in patients with hereditary hemorrhagic telangiectasia. ${ }^{13}$ Olitsky had also reported another similar finding and suggested that topical Timolol could be another treatment option for epistaxis in patients with hereditary hemorrhagic telangiectasia. ${ }^{14}$

The hemostatic effect of propranolol could be explained through antagonizing beta- 1 adrenoceptors, and thus, lowering stroke volume and blood pressure, which are frequently elevated in patients with epistaxis. ${ }^{6}$ Moreover, peripheral vasoconstriction, which is an adverse effect of propranolol due to its possible alpha-2 adrenergic receptor antagonist activity, is a potentially desirable feature in epistaxis and some other bleeding disorders with no life-threatening consequences. ${ }^{6,7,15,16}$ An accumulating evidence for propranolol to have strong antiangiogenic effect is readily available and has been introduced as a treatment modality for proliferating hemangiomas and some other solid neoplastic proliferations. ${ }^{17-19}$ Such antiangiogenic effect of propranolol has been attributed to some of its possible pathophysiologic mechanisms such as vasoconstriction; decreased expression of basic fibroblast growth factor, matrix metalloproteinase, and vascular endothelial growth factor; and upregulation of apoptosis of capillary endothelial cells. ${ }^{20}$ Another possible mechanism for the effectiveness of propranolol in the management of epistaxis might be related to its potential indirect alpha-1 agonist effect, which can indirectly provoke vasoconstriction of the systemic veins. ${ }^{7,21}$

Our finding that children treated with silver nitrate cautery needed increased use of analgesic makes sense, owing to the nature of the chemical burn produced by the cautery procedure and the varying degrees of cooperation and tolerance of treated children for such pain.

Treatment failure among both groups was insignificantly different when compared to each other. Moreover, within the

Table 3 Some studied variables among silver nitrate cautery treatment group

\begin{tabular}{llll}
\hline $\begin{array}{l}\text { Number of } \\
\text { patients }\end{array}$ & $\begin{array}{l}\text { Age group } \\
\text { (years) }\end{array}$ & Rhinoscopy findings & Epistaxis recurrence $^{\text {a }}$ \\
\hline 9 & 6 to $<7$ & Unilateral dilated vessels on the anterior nasal septum & $\begin{array}{l}\text { One case in the third month } \\
\text { One case in the first month }\end{array}$ \\
10 & 7 to $<8$ & Unilateral crusting & No recurrence \\
8 & 8 to $<9$ & Unilateral crusting & One case of severe bleeding in the first week \\
7 & 9 to $<10$ & Bilateral prominent vessels on the anterior nasal septum & Two cases in the last month \\
8 & 10 to $<11$ & Bilateral prominent vessels on the anterior nasal septum & One case after 4 months \\
8 & 11 to $<12$ & Bilateral prominent vessels on the anterior nasal septum & Ont
\end{tabular}

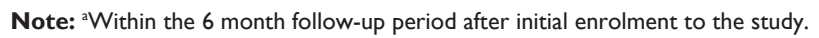


Table 4 Comparison of rate of epistaxis recurrence in propranolol treatment group and silver nitrate cautery treatment group

\begin{tabular}{llll}
\hline P-value & $\begin{array}{l}\text { Silver nitrate } \\
\text { cautery } \\
\text { treatment group }\end{array}$ & $\begin{array}{l}\text { Propranolol } \\
\text { treatment } \\
\text { group }\end{array}$ & Variables \\
\hline NS & 50 & 50 & $\begin{array}{l}\text { Total number of patients } \\
\text { Necurrence of epistaxis }\end{array}$ \\
NS & $6(12 \%)$ & $7(14 \%)$ & \begin{tabular}{l} 
(number of cases) \\
\hline
\end{tabular} \\
\hline
\end{tabular}

Notes: NS, nonsignificant $(P>0.05)$. ${ }^{a}$ Within the 6 month follow-up period after initial enrolment to the study.

propranolol treatment group, patients who did not respond were only seven patients, representing only $14 \%$ of this group, with variable duration of treatment failure ranging from immediately after therapy discontinuation up to the last month of follow-up, as shown in Table 2. Furthermore, we could not find specific criteria or differences for those who failed propranolol therapy owing to the statistical difficulties to compare seven patients who failed propranolol therapy with variable durations of failure to 43 patients who responded up to 6 months of follow-up after getting enrolled in the study.

\section{Conclusion}

Primary recurrent epistaxis with nonlife-threatening bleeding or comorbid conditions can be managed medically with oral propranolol, with no side effects or local nasal pain associated with the commonly used cauterization with $25 \%$ silver nitrate. Recurrence rate of epistaxis showed no significant difference when treated with propranolol compared to silver nitrate cauterization.

It is not ethical to treat a patient with epistaxis with a placebo treatment, as standard therapies are well known and available. Ethical considerations in such cases did not allow comparison of propranolol therapy to a placebo therapy, to further clarify the efficacy and safety of propranolol therapy.

\section{Recommendations}

Propranolol could be an alternative choice for the management of primary epistaxis in children when the settings and availability of specialized ENT physician are limited, especially in our locality as a developing country. Further studies involving multiple centers and more number of patients over longer durations are highly recommended for more clarification for the efficacy and safety of propranolol in the management of primary idiopathic recurrent epistaxis in children.

\section{Strengths and limitations}

This study is a randomized controlled prospective study, which gives it a reasonable strength as an evidence that can open the window for more wide randomized trials for the same idea and principle. To the best of our knowledge and search, we could not find studies or reports that compare the use of propranolol to the use of conventional silver nitrate cautery in the management of primary, idiopathic, recurrent epistaxis in children. Moreover, our study added to the evidence of efficacy of propranolol to manage primary idiopathic recurrent epistaxis in children, similar to other conventional methods, with no side effects.

Our limitations include being a single center trail, relatively limited number of patients, and difficulty in generalizing our findings at all situations and circumstances. The limited number of patients who did not respond to either therapy did not allow us to find specific characters or risk factors that might predict risk of therapy failure in either groups.

\section{Author contributions}

Ahmed E Ahmed: conception and design, literature review, acquisition of data and analysis, drafting the article, and final approval of the version published; Essam A Abo El-Magd: conception and design, literature review, interpretation of data, major contribution to the writing of the paper, and final approval of the version published; Gamal M Hasan: revising the article critically for important intellectual content, interpretation of data, English editing review, final approval of the version published, and correspondence for the publication; Osama M El-Asheer: revising the article critically for important intellectual content, interpretation of data, and final approval of the version published.

\section{Acknowledgment}

There was no specific funding resource as the study interventions (investigations and therapies) were readily available within the institutions where the study was carried out. Other requisites for the study were negligible and provided by the authors themselves.

\section{Disclosure}

The authors report no conflicts of interest in this work.

\section{References}

1. Al Khtoum N, Al Roosan M. The evaluation of conservative measures in the treatment of epistaxis. Khartoum Med J. 2008;1(1):15-17.

2. Moreau S, De Rugy MG, Babin E, Courtheoux P, Valdazo A. A supraselective embolization in intractable epistaxis: a review of 45 cases. Laryngoscope. 1998;108(6):887-888.

3. Soyka MB, Nikolaou G, Rufibach K, Holzmann D. On the effectiveness of the treatment options in epistaxis: an analysis of 678 interventions. Rhinology. 2011;49(4):474-478.

4. Guarisco JL, Graham HD. Epistaxis in children: the causes, diagnosis and the treatment. Ear Nose Throat J. 1989;68(7):522, 528-530, 532 assim. 
5. Brown NJ, Berkowitz RG. Epistaxis in healthy children requiring hospital admission. Int J Pediatr Otorhinolaryngol. 2004;68(9):1181-1184.

6. Melia L, McGarry GW. Epistaxis: update on management. Curr Opin Otolaryngol Head Neck Surg. 2011;19(1):30-35.

7. Young R, Glennon RA. Propranolol as a discriminative stimulus and its comparison to the stimulus effects of cocaine in rats. Psychopharmacology. 2009;203(2):369-382.

8. Hoag JB, Terry P, Mitchell S, Reh D, Merlo CA. An epistaxis severity score for hereditary hemorrhagic telangiectasia. Laryngoscope. 2010;120: 838-843.

9. Bailie N, Hanna B, Watterson J, Gallagher G. A model of the airflow in the nasal cavities: the implications for the nasal air conditioning and epistaxis. Am J Rhinol Allergy. 2009;23(3):244-249.

10. Tam S, Rotenberg B. Contemporary perspectives on the management of posterior epistaxis: a survey of Canadian otolaryngologists. J Otolaryngol Head Neck Surg. 2011;40(3):249-255.

11. Vis E, van den Berge H. The treatment of epistaxis without the use of a nasal packing; a patient study. Rhinology. 2011;49(5):600-604.

12. Bjelakovic B, Bojanovic M, Lukic S, et al. The therapeutic efficacy of propranolol in children with recurrent primary epistaxis. Drug Des Devel Ther. 2013;7:127-129.

13. Albinana V, Recio-Poveda L, Zarrabeitia R, Bernabéu C, Botella LM. Propranolol as antiangiogenic candidate for the therapy of hereditary haemorrhagic telangiectasia. Thromb Haemost. 2012;108:41-53.

14. Olitsky SE. Topical Timolol for the treatment of epistaxis in hereditary hemorrhagic telangiectasia. Am J Otolaryngol. 2012;33:375-376.
15. Scheibe M, Wüstenberg EG, Hüttenbrink KB, Zahnert T, Hummel T. Studies on the effects of ice collars on nasal blood volume using optical rhinometry. Am J Rhinol. 2006;20(4):394-396.

16. Dagher L, Burroughs A. Variceal bleeding and portal hypertensive gastropathy. Eur J Gastroenterol Hepatol. 2001;13(1):81-88.

17. Léauté-Labrèze C, Dumas de la Roque E, Hubiche T, Boralevi F, Thambo JB, Taïeb A. Propranolol for severe hemangiomas of infancy. N Engl J Med. 2008;12358(24):2649-2651.

18. Annabia B, Lachambre MP, Plouffe K, Moumdjian R, Béliveau R. Propranolol adrenergic blockade inhibits human brain endothelial cells tubulogenesis and matrix metalloproteinase-9 secretion. Pharmacol Res. 2009;60(5):438-445.

19. Lamy S, Lachambre MP, Lord-Dufour S, Beliveau R. Propranolol suppresses angiogenesis in vitro: inhibition of proliferation, migration, and differentiation of endothelial cells. Vascul Pharmacol. 2010;53(5-6): 200-208.

20. Pasquier E, Ciccolini J, Carre M, et al. Propranolol potentiates the antiangiogenic effects and anti-tumor efficacy of chemotherapy agents: implication in breast cancer treatment. Oncotarget. 2011;2(10): 797-809.

21. Sloand EM, Thompson BT. Propranolol-induced pulmonary edema and shock in a patient with pheochromocytoma. Arch Intern Med. 1984;144(1):173-174.
Adolescent Health, Medicine and Therapeutics

\section{Publish your work in this journal}

Adolescent Health, Medicine and Therapeutics is an international, peer-reviewed, open access journal focusing on health, pathology, and treatment issues specific to the adolescent age group. All aspects of health maintenance, preventative measures and disease treatment interventions are addressed within the journal and practitioners from

\section{Dovepress}

all disciplines are invited to submit their work as well as healthcare researchers and patient support groups.. The manuscript management system is completely online and includes a very quick and fair peerreview system. Visit http://www.dovepress.com/testimonials.php to read real quotes from published authors. 